\title{
Slope Stability Analysis of the Gbeni Earth Dam (GB3) in Rutile - Sierra Leone
}

\author{
Simeon Stevenson Turay, Osman Koroma, Abdul Ahmed Koroma
}

Department of Civil Engineering, University of Sierra Leone, Freetown, Sierra Leone

Email addresses:

turaysimeonstevenson@gmail.com (S. S. Turay), osmankoroma002@gmail.com (O. Koroma), aakoroma@mtu.edu (A. A. Koroma)

To cite this article:

Simeon Stevenson Turay, Osman Koroma, Abdul Ahmed Koroma. Slope Stability Analysis of the Gbeni Earth Dam (GB3) in Rutile - Sierra Leone. International Journal of Materials Science and Applications. Vol. 9, No. 6, 2020, pp. 66-70. doi: 10.11648/j.ijmsa.20200906.11

Received: June 21, 2020; Accepted: July 10, 2020; Published: December 16, 2020

\begin{abstract}
Earth slopes stability analysis is important in the design and construction of earth dams under different loading conditions. Several factors such as difference in water level or rapid drawdown in the reservoir, right after construction, and steady - state seepage may result in instability of Earth Dams for all possible combinations. In this study, three scenarios were evaluated for the Gbeni Earth Dam (GB3) at Sierra Rutile Mining Company in Sierra Leone. It is a zoned earth-filled embankment dam with respective upstream and downstream slopes of 1:3 and 1:2, having a horizontal sand blanket downstream. The upstream slope was subjected to both rapid drawdown in the reservoir of the earth dam and end of construction condition when there is no water present in the reservoir, whilst the downstream slope was assessed for steady seepage and end of construction conditions. The shape of the critical slip surface of both slopes was evaluated using a circular failure surface. The objective of this study was to assess the stability of these slopes under the above conditions using traditional analysis according to the theory of limit states and safety factor in GEO 5 software and its subprograms. The level of water on the upstream and downstream banks, the geotechnical properties of soil materials and boundary conditions of the dam were used as contribution variables and safety factors as the desired output. The study found out that the factor of safety against sliding of the upstream slope marginally drops within the short period after the start of rapid drawdown of water in the reservoir of the dam. Also, the downstream slope was found to be more stable under steady seepage. This accounts for the uncertainties involved in the strength of material, pore pressures in impervious clay core material, and long-term loading condition.
\end{abstract}

Keywords: Rapid Drawdown, Steady - State Seepage, Limit States Equilibrium, Safety Factor, GEO 5 Software

\section{Introduction}

Sierra Rutile Mining Company is one of the oldest mining companies in Sierra Leone that relies on dams for various mining processes. The company has well over thirty dams, ranging from earth-filled to tailings that have existed for many years. Gbeni Earth Dam is the third water storage dam within the Gbeni area, one of the company's mining environments. The dam is $300 \mathrm{~m}$ long, $100 \mathrm{~m}$ wide and $18 \mathrm{~m}$ high with $1: 3$ upstream and 1:2 downstream slopes. A $25 \mathrm{~m}$ wide and $100 \mathrm{~m}$ long horizontal sand drainage blanket was also incorporated at the downstream grade in order to handle seepage of water within the dam. GB3 Earth dam was designed to handle an estimated volume of $5,386,000 \mathrm{~m}^{3}$ of water.

In order to investigate the stability of an Earth dam, it is necessary to run a thorough evaluation of the slopes under different loading conditions. Craig, (2004) maintained that, assessing the stability of earth slopes is key in defining their behavior at the end of all possible loading conditions [3].

For slope stability analysis, the verification methodology of structure safety based on the factor of safety is historically the oldest and most widely used approach. According to Stark \& Jafari, (2017), the principal advantage is its simplicity and rationality [11]. When performing the analysis using this method, neither the load nor the soil parameters are reduced by any of the design coefficients. The factor of safety represents the ratio of total available shear strength of the soil to shear stress required to maintain equilibrium along a potential surface of sliding. This factor indicates a relative measure of how stable a slope is under various loading combinations, However, it does not precisely indicate the actual margin of safety. It follows that a relatively large factor of safety implies relatively low shear stress levels in the embankment or foundation and, hence, relatively small 
deformations. Das, (2007) suggests that, the minimum factors of safety for use in the design of slope stabilization should follow rationally from an assessment of several factors, which include the extent of planned monitoring of pore pressures and assumptions and uncertainties involved in the strength of construction material [4].

According to Terzaghi \& Peck., (1948), there are different slope stability assessment methods. In this study, an effective stress state of soil properties was used, and the most critical slip circle centre according to Bishop, Fellenius/Peterson, Spenser, Janbu, and Morgenstern-Price methods was determined [12]. With these methods in GEO 5 computer program, the potential slip surface and safety factors of the GB3 earth dam were determined for all probable loading combinations.

\section{Methodology}

\subsection{Case Analysis and Loading Conditions}

This study was performed using traditional analysis according to the theory of limit states and safety factor in GEO 5 software and its subprograms in assessing the stability of both upstream and downstream slopes by subjecting each slope to the appropriate loading conditions. Consideration was given to all loading conditions which may result in instability of the GB3 water storage earth dam.

\subsection{Rapid Drawdown Condition in the Reservoir}

Slope stability analysis during the rapid drawdown in the reservoir is an important consideration in the design of earth dams. Fluctuations in reservoir water level may cause stability issues to the upstream grade mainly as a result of the removal of the supporting water. Ground water specified within the slope body using any one of the five analysis options influences the analysis in two different ways, when calculating the weight of the soil mass and when defining the shear forces. When the reservoir is rapidly emptied and drawn down, the stabilizing effect of the water on the upstream face is lost, but the pore-water pressures within the embankment may remain high. As a result, the stability of the upstream face of the dam can be much reduced. According to Bishop \& Bjerrum, (1960) and Craig, (2004), rapid drawdown is an important condition controlling the design of the upstream slope in embankment dams [1-3]. In particular, slides due to rapid drawdown can lead to reduced reservoir capacity and dam failure. In their book on earth and earthrock dams, Sherard et al., (1963) describe several upstream slope failures attributed to rapid drawdown conditions [10]. In this study, the 1:3 upstream slope of the GB3 Earth Dam was subjected to this condition and analyzed in GEO 5 software and its subprograms.

\subsection{End of Construction Condition}

For earth Dams, the critical condition to be analyzed is at the completion of embankment dam construction but before filling with water. In this case, there is no water table present in the reservoir and in the body of the dam. For this loading case, Khanna et al., (2014) maintained that excess pore pressures may be induced in impervious zones of the embankment or foundation [8]. As a result of this, the stability of both the 1:3 upstream and 1:2 downstream slopes was analyzed for this loading condition.

\subsection{Steady State Seepage Condition}

When an earth dam is constructed, especially when the reservoir is full of water, there is some steady seepage within and into the embankment. To assess the effect of this condition and the uncertainties involved in material strengths, pore pressures in impervious material such as the incorporated core zone, and long-term loading, the stability of the 1:2 downstream slope of the Gbeni Earth Dam was evaluated for this loading condition. The material properties of the various zones of the dam are presented in Table 1 below.

Table 1. Properties of the Embankment Soil and Sand Drain Material.

\begin{tabular}{llll}
\hline Material Type & Unit Weight $\left(\mathbf{K N} / \mathbf{m}^{\mathbf{3}}\right)$ & Cohesion $\left(\mathbf{K N} / \mathbf{m}^{2}\right)$ & Angle of Internal Friction $\left.\mathbf{(}^{\circ}\right)$ \\
\hline Clay Core & 19 & 40 & 10 \\
Shell & 19 & 10 & 35 \\
Sand Blanket & 19 & 10 & 35 \\
Foundation & 19 & 10 & 35 \\
\hline
\end{tabular}

\section{Results and Discussion}

In this slope stability analyses of the GB3 Earth Dam, the effective stress state soil properties were used, and the most critical slip circle centre according to five analysis methods was considered. The factor of safety against failure of both upstream and downstream slopes of the Earth Dam for three discrete loading conditions was evaluated according to Bishop, Fellenius/Peterson, Spenser, Janbu, and Morgenstern-Price methods. This section, therefore, presents discussion of the results obtained from GEO 5 computer program and its subprograms.

\subsection{Stability of Upstream Slope - End of Construction and Rapid Drawdown Conditions}

The upstream slope of the Gbeni Earth Dam was built to two loading conditions; the end of construction (dry condition) when there is no water table present in the reservoir and the embankment dam body and the rapid drawdown condition in the reservoir of the earth dam. Typical failure surfaces for the stability of this slope under both conditions and safety factors obtained during the analysis are presented below. 
Table 2. Factors of Safety for the Upstream Slope End of Construction and Rapid Drawdown Conditions.

\begin{tabular}{llllll}
\hline Loading Condition & Bishop & Fellenius & Spenser & Janbu & Morgenstern \\
\hline End of construction & 2.37 & 2.27 & 2.43 & 2.46 & 2.46 \\
Rapid Drawdown & 1.87 & 1.79 & 1.93 & 1.96 & 1.96 \\
\hline
\end{tabular}

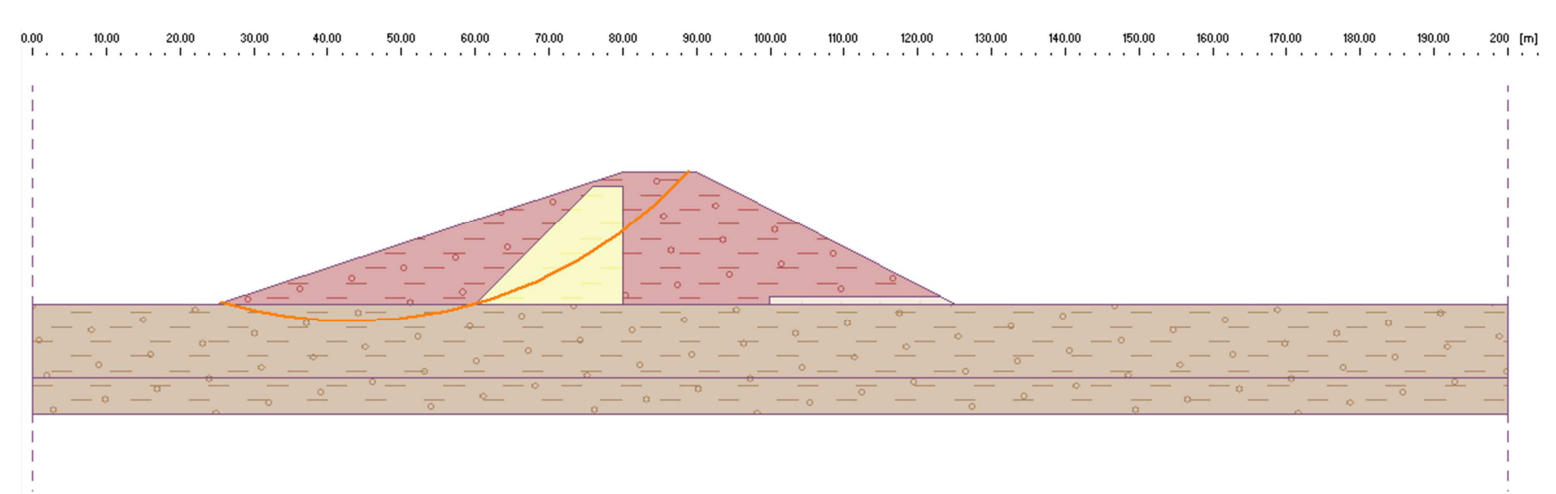

Figure 1. Critical Failure Surface for Upstream Slope End of Construction Condition.

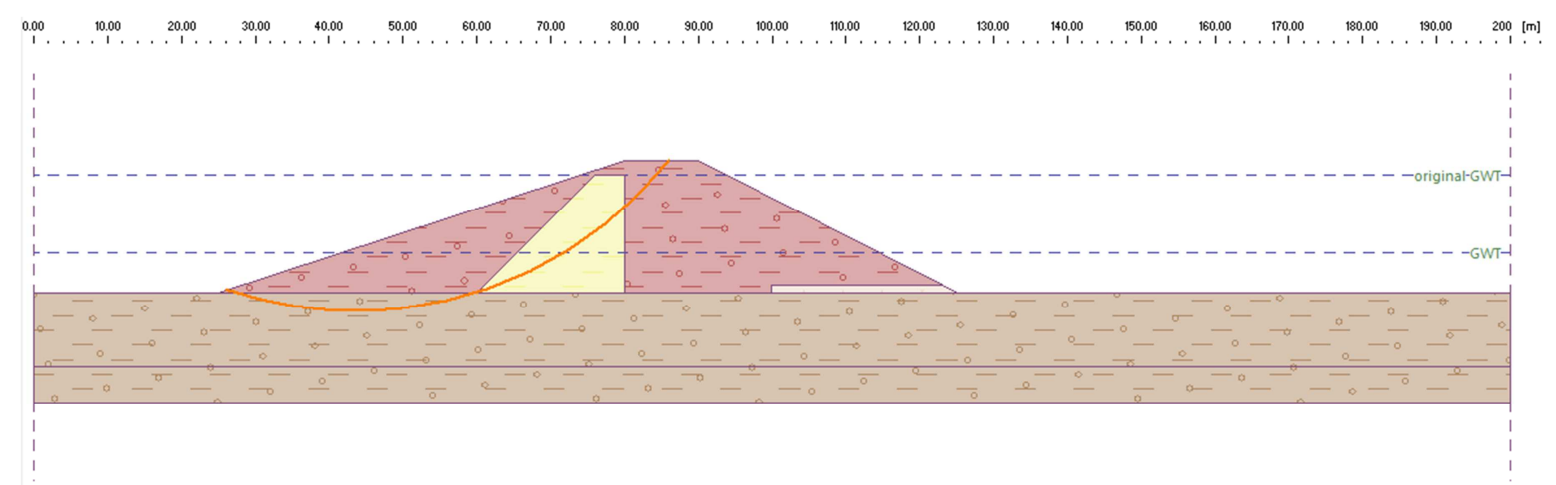

Figure 2. Critical Failure Surface for Upstream Slope Rapid Drawdown Condition.

\subsection{Stability of Downstream Slope - End of Construction and Steady Seepage Conditions}

The downstream slope of the GB3 Earth Dam was also built to two loading conditions; the end of construction (dry condition) when there is no water table present in the reservoir and in the embankment dam body and to steady state seepage condition when the reservoir is full of water. Typical failure surfaces for the stability of the downstream slope under both conditions and safety factors obtained during the analysis are presented below.

Table 3. Factors of Safety for the Downstream Slope End of Construction and Steady-State Seepage Conditions.

\begin{tabular}{|c|c|c|c|c|c|}
\hline Condition & Bishop & Fellenius & Spenser & Janbu & Morgenstern \\
\hline End of construction & 1.89 & 1.83 & 1.89 & 1.89 & 1.89 \\
\hline Steady Seepage & 2.12 & 2.02 & 2.12 & 2.12 & 2.12 \\
\hline
\end{tabular}

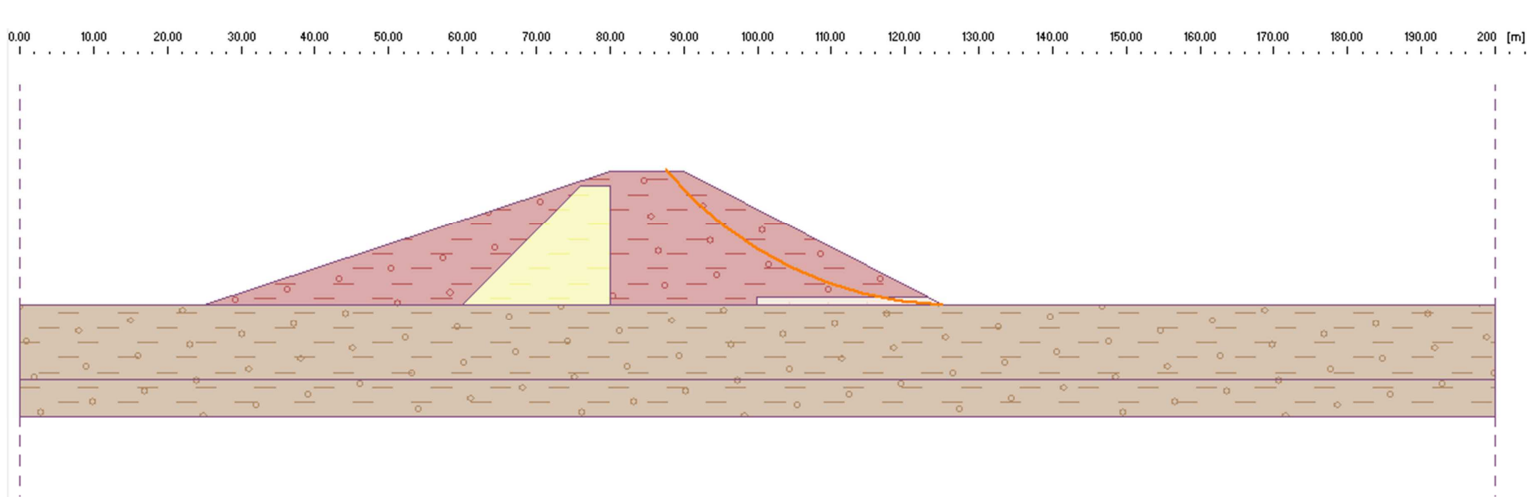

Figure 3. Critical Failure Surface for Downstream Slope End of Construction Condition. 


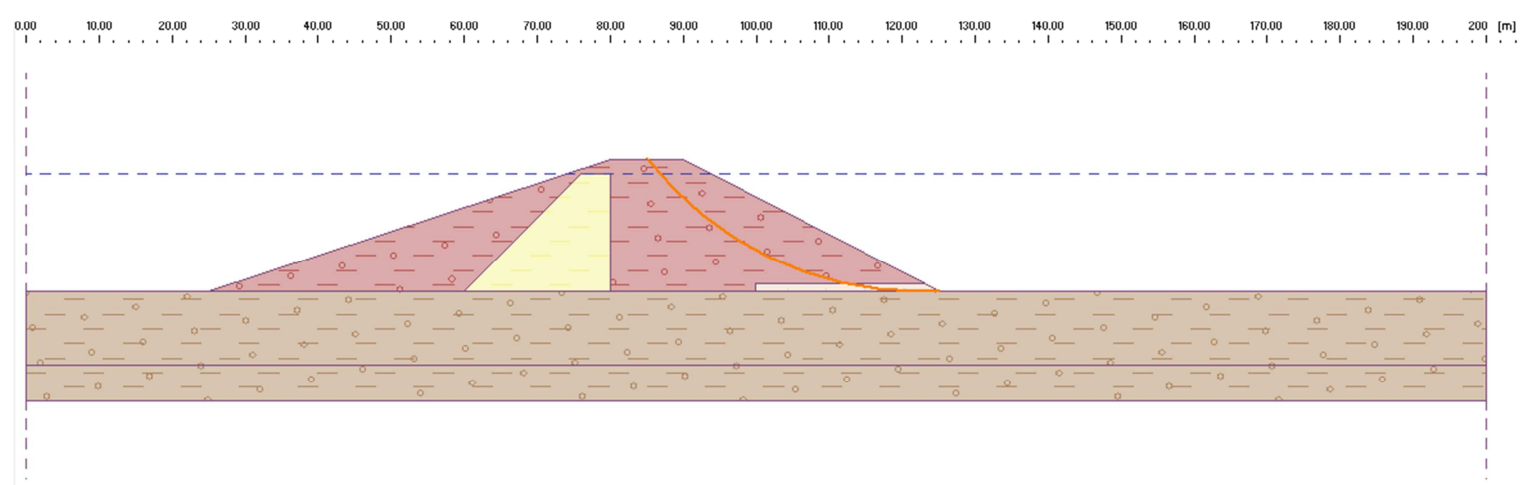

Figure 4. Critical Failure Surface for Downstream Slope Steady State Seepage Condition.

The factors of safety for all methods under the three discrete loading conditions are greater than the minimum acceptable value of 1.5 as put forward by (Coduto, 1999)[2]. The factor of safety against sliding of the upstream slope was found to decrease immediately when the dam was subjected to a rapid drawdown of water in the reservoir. This was as a result of the dissipation of excess pore pressure with time. It leads to an increase in effective stresses in the soil and hence an increase in its shear stress. Loading due to unbalanced seepage forces may have rendered the upstream slope unstable; since the reservoir level is reduced during the rapid drawdown of water. From the five analysis methods, Fellenius was found to present the minimum safety factor for all loading conditions of both upstream and downstream slopes. The soils at the GB3 Dam are not homogeneous as put forward by (Fellenius, 1936) [7]. The presence of water tables and pore water pressures at the dam are not taken into account. As a result, the determination of the location of the most critical slip circle centre in the earth embankment dam by using Fellenius method could not be accurate enough. However, this determination provides a benefit in reducing the number of computational trials. The difference between the various analysis methods is less than $6 \%$ as put forward by (Duncan, 1996) [5]. In fact, safety factors obtained from Janbu and Morgenstern analysis methods are seen to agree fairly well for all loading conditions.

\section{Conclusion}

Based on the slope stability analysis results, the following conclusions can be deduced when considering the three examined construction and / or loading conditions:

The GB3 Earth Dam is stable under all probable loading conditions.

The overall minimum stability factor for the end of construction loading case of the upstream slope of the earth Dam but before filling with water was 2.28. This provides stability of the upstream slope against sliding failure under this condition.

The overall minimum stability factor for the rapid drawdown loading case of the upstream slope of the earth Dam was 1.79 . This implies stability of the upstream slope against sliding failure under this condition.
The overall minimum stability factor for the end of construction loading case of the downstream slope of the earth Dam but before filling with water was 1.83 . This implies stability of the upstream slope against sliding failure under this condition.

The overall minimum stability factor for the steady-state seepage loading case of the downstream slope of the earth Dam but prior to filling with water was 2.02. This implies stability of the upstream slope against sliding failure under this condition.

The factor of safety against sliding of the upstream slope was found to decrease immediately when the dam was subjected to rapid drawdown of water in the reservoir. This was as a result of the dissipation of excess pore pressure with time. It leads to an increase in effective stresses in the soil and hence an increase in its shear stress. Loading due to unbalanced seepage forces may have contributed to this reduction; since the reservoir level is reduced during the rapid drawdown.

The difference between the various analysis methods is less than $6 \%$ as put forward by (Duncan, 1996) [5]. In fact, safety factors obtained from Janbu and Morgenstern analysis methods are seen to agree fairly well for all loading conditions.

Though stable, the upstream slope if subjected to constant evacuation of water from the reservoir may be exposed to collapse in the long term.

\section{References}

[1] Bishop, A. W., \& Bjerrum, L. (1960). The relevance of the triaxial test to the solution of stability problems. Proc. Research Conference Shear Strength of Cohesive Soils, (pp. 437-501).

[2] Coduto, D. P. (1999). Geotechnical Engineering Principles and Practices. New Jersey: Alan Apt.

[3] Craig, R. F. (2004). Craig's Soil Mechanics (7th ed.). Spon Press.

[4] Das, B. M. (2007). Advanced Soil Mechanics (Third ed.). Taylor \& Francis.

[5] Duncan, J. M. (1996). State of the Art: Limit equilibrium and finite element analysis of slopes. J. Geotech. Eng, ASCE, 122, 577-596. 
[6] Fattah, M. Y., Omran, H. A., \& Hassan, M. A. (2015). Behavior of an Earth Dam during Rapid Drawdown of Water in Reservoir - Case Study. International Journal of Advanced Research, 110-122.

[7] Fellenius, W. (1936). Calculation of the Stability of Earth Dams. Transactions, 2nd International Congress on Large Darns (pp. 445-459). Washington, DC: International Commission on Large Dams.

[8] Khanna, R., Datta, M., \& Ramana, G. V. (2014). End-ofconstruction stability of earth and rockfill dams. Proceedings of Indian Geotechnical Conference IGC-2014. Kakinada, India.
[9] Paton, J., \& Semple, N. G. (1961). Investigation of the stability of an earth dam subjected to rapid drawdown including details of pore pressure recorded during a controlled drawdown test. Pore pressure and suction in soils. 85-90.

[10] Sherard, J. L., Woodward, R. J., Gizienski, S. F., \& Clevenger, W. A. (1963). Earth and earth-rock dams. New York: John Wiley and Sons.

[11] Stark, T. D., \& Jafari, N. H. (2017). Rapid Drawdown Stability Analysis of San Luis Dam. 3rd North American Symposium on Landslides. Roanoke, Virginia, USA.

[12] Terzaghi, K., \& Peck, R. B. (1948). Soil Mechanics in engineering practice. New York: Wiley. 